\title{
MULTI-COMPONENT QUANTITATION OF LORATADINE, PSEUDOEPHEDRINE AND PARACETAMOL IN PLASMA AND PHARMACEUTICAL FORMULATIONS WITH LIQUID CHROMATOGRAPHY-TANDEM MASS SPECTROMETRY UTILIZING A MONOLITHIC COLUMN
}

\author{
Kamran Abro \\ National Centre of Excellence in Analytical Chemistry, University of Sindh Jamshoro, 76080 / Pakistan Council of Scientific and \\ Industrial Research Laboratories Complex, 75280, Karachi Pakistan \\ Najma Memon* and M. I. Bhanger \\ National Centre of Excellence in Analytical Chemistry, University of Sindh Jamshoro, 76080, Pakistan \\ Shahnaz Perveen and Aftab Kandhro \\ Pakistan Council of Scientific and Industrial Research Laboratories Complex, 75280, Karachi Pakistan
}

Recebido em 16/2/12; aceito em 5/7/12; publicado na web em 25/9/12

\begin{abstract}
The purpose of this study was to develop a rapid, simple and sensitive quantitation method for pseudoephedrine (PSE), paracetamol (PAR) and loratadine (LOR) in plasma and pharmaceuticals using liquid chromatography-tandem mass spectrometry with a monolithic column. Separation was achieved using a gradient composition of methanol- $0.1 \%$ formic acid at a flow rate of $1.0 \mathrm{~mL}$ $\mathrm{min}^{-1}$. Mass spectral transitions were recorded in SRM mode. System validation was evaluated for precision, specificity and linearity. Limit of detection for pseudoephedrine, paracetamol, and loratadine were determined to be 3.14, 1.86 and $1.44 \mathrm{ng} \mathrm{mL}^{-1}$, respectively, allowing easy determination in plasma with \% recovery of 93.12 to $101.56 \%$.
\end{abstract}

Keywords: antihistamines; decongestants; liquid chromatography-tandem MS.

\section{INTRODUCTION}

Antihistamines are the class of drugs prescribed to deal with the skin and other allergic reactions occurring due to seasonal changes. Sedating effects of first generation antihistamines has limit their use, and consequently second generation antihistamines are now commonly prescribed by practitioners. LOR is a second generation antihistamine and is one of the most prescribed of the antihistamine drugs. ${ }^{1}$ PSE is classified as a decongestant drug that acts as a sympathomimetic agent. ${ }^{2}$ PAR is an analgesic and antipyretic drug used to relieve pain and fever. ${ }^{3,4}$ The combination therapies of LOR with PSE, and PSE with PAR, have long been prescribed to treat cold and allergic reactions due to seasonal changes. The quantitative determination of these drugs in plasma samples is of importance for pharmacokinetic activity and other assays of biological interest.

HPLC and liquid chromatography-tandem mass spectrometry (LC-MS/MS) are the most widely used analytical techniques for the determination of PSE, PAR and LOR in pharmaceutical and biological matrices. LC-MS/MS in particular, is the most popular analytical technique primarily because of its inherent selectivity and sensitivity. ${ }^{5-17}$ The other techniques including capillary electrophoresis, ion-pair LC and ion mobility spectrometry have also been utilized for the determination of pseudoephedrine with other drugs in various biological and pharmaceutical samples. ${ }^{18-20}$

Evaluations of monolithic columns have shown them to be equivalent to commercially available particle packed columns in terms of high binding capacity, high flow rates with low back pressure leading to fast separations, higher mass transfer kinetics, and increased efficiency. ${ }^{21}$ The most important characteristic distinguishing monolith from particulate columns is that the former can be operated at high flow rates without compromising the system suitability parameters. $22-24$

The other parameter that limits high throughput of plasma

*e-mail: najmamemon@ceacsu.edu.pk samples in clinical diagnosis is the time consuming sample treatment procedure. The direct protein precipitation procedure is a robust, reliable and quick alternative for the determination of selected components as compared to multi-step sample processing procedures like liquid-liquid and solid phase extraction. Many articles are available reporting the simultaneous determination of LOR with Des-LOR, $, 5,6,15$ PSE with LOR ${ }^{7}$ and PSE with PAR or others ${ }^{9,12,16}$ but to the best of our knowledge not a single method has been reported for the multi-component determination of all these components in plasma and pharmaceutical formulations utilizing a monolithic column.

This study was carried out with the aim of multi-component determination of PSE, PAR and LOR, with chlorpheniramine (CPM) as an internal standard (IS), in plasma and pharmaceutical formulations using the LC-ESI-MS/MS technique in SRM mode. The method has been optimized and validated systematically for the routine analysis of clinical samples.

\section{EXPERIMENTAL}

\section{Chemicals and reagents}

PSE, PAR, LOR and CPM standards were obtained from various pharmaceuticals of Karachi, Pakistan. The purity of all the pharmaceutical standards was $>99 \%$. HPLC grade methanol and formic acid were purchased from Merck KGaA, Darmstadt, Germany. Millipore quality water (conductivity below $0.1 \mu \mathrm{S}$ generated by reverse osmosis) was used for this study. Mobile phase components were all degassed using Super Sonic X-3 sonicator before use.

\section{Instrumentation}

LCQ Advantage Max with an ion trap mass analyzer coupled to a SurveyorPlus pump, SurveyorPlus photodiode detector and SurveyorPlus degasser of Thermo Finigan (Thermo Electron Corporation, San Jose, California) was used for the present study. 
Xcalibur 2.0 SR2 software was used for data analysis. Separation was achieved using a Chromolith ${ }^{\circledR}$ Performance RP-18e column $(100 \times$ $4.6 \mathrm{~mm}$ ) by Merck KGaA, Darmstadt, Germany. Vortex mixing was carried out using a VM-300 vortex mixer (Gemmy Industrial Co. Taipei Taiwan) and centrifugations were performed on a Sigma 3-18 K centrifuge (Sigma, Osterode am Harz, Germany). Super Sonic X-3 sonicator was used in the current study.

\section{Standard and sample preparation}

\section{Standard preparation}

The stock standard solutions of PSE, PAR, LOR and CPM (IS) were prepared in methanol at the concentration of $1.0 \mathrm{mg} \mathrm{mL}^{-1}$. The working standard solutions were prepared by diluting aliquots of each stock solution in methanol to obtain the required concentrations.

\section{Sample preparation}

\section{Pharmaceutical formulations}

For pharmaceutical samples, two brands of pharmaceutical tablets were purchased from a local pharmacy in Karachi, Pakistan. One tablet contained PSE $60 \mathrm{mg}$ and LOR $5 \mathrm{mg}$ in combination therapy and the other contained only PAR $400 \mathrm{mg}$. 10 tablets from each sample were finely ground individually and three different portions of PSE, LOR and PAR were taken from these for the assay analysis. The portions of tablets were placed in a volumetric flask and made up to the mark with methanol and sonicated for $10 \mathrm{~min}$. The resultant mixture was then filtered through $0.45 \mu \mathrm{m}$ filter paper and a volume of $25 \mu \mathrm{L}$ was injected into the LC-ESI-MS/MS for further analysis.

\section{Plasma samples}

Plasma samples were analyzed directly after deproteinization. Plasma samples $(300 \mu \mathrm{L})$ and $100 \mu \mathrm{L}$ of mixed standards (contai-

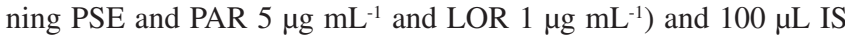
$\left(5 \mu \mathrm{g} \mathrm{mL}^{-1}\right)$ were added. The mixture was vortex mixed for $1 \mathrm{~min}$ and $500 \mu \mathrm{L}$ of acetonitrile were added. The mixture was vortex mixed again and centrifuged at $1900 \mathrm{~g}$ for $5 \mathrm{~min}$. The supernatant was collected and filtered through $0.45 \mu \mathrm{m}$ filter paper and a volume of $25 \mu \mathrm{L}$ was injected into the LC-ESI-MS/MS for further analysis.

\section{Procedure for separation and identification}

PSE, PAR and LOR were separated on a Chromolith ${ }^{\circledR}$ Performance RP-18e column using step gradient elution with solvent A (methanol) and B (0.1\% formic acid). Elution started at $40 \% \mathrm{~A}(\mathrm{v} / \mathrm{v})$ and was isocratic for $5 \mathrm{~min}$ and then step gradients from 40 to $80 \%$ A (v/v) were used for $5 \mathrm{~min}$. Mobile phase A was then brought back to $40 \%$ A (v/v) for 2 min so as to regenerate the column conditions. The flow rate was $1.0 \mathrm{~mL} \mathrm{~min}^{-1}$ and total analysis time was $12 \mathrm{~min}$. The injection volume was $25 \mu \mathrm{L}$ and the temperature of the auto-sampler tray and column thermostat was set to $25^{\circ} \mathrm{C}$.

Mass spectrometric conditions were optimized individually for all components and were analyzed in different segments so as to enhance sensitivity and selectivity. The $100 \%$ of flow rate was transferred to the mass spectrometer and mass spectral transitions were as follows: ESI in positive mode with spray voltage of $4.5 \mathrm{kV}$, capillary temperature $225^{\circ} \mathrm{C}$, sheath and aux/sweep gas flow of 75 and 25 arbitrary units, respectively.

\section{Quantitation}

Quantitation of PSE, PAR and LOR in plasma samples was carried out using the internal standard method while in pharmaceutical formulations external standard calibration was employed. An IS (100 ng $\mathrm{mL}^{-1} \mathrm{CPM}$ ) was added to the sample preparation procedure. Seven point mixed standard curves of $0.078,0.156,0.312,0.625,1.25$, 2.5 and $5.0 \mu \mathrm{g} \mathrm{mL}^{-1}$ were constructed using Xcalibur QuanBrowser (version 2.0) software for the quantitation of selected drugs in the plasma samples.

\section{RESULTS AND DISCUSSION}

\section{Optimization of separation and identification conditions}

One of the objectives of the study was to employ a monolithic column (i.d. $4.6 \mathrm{~cm}$ ) for the separation of PSE, PAR and LOR using mass detection. To carry out the separation, methanol was used as mobile phase and ESI mode in MS was set which easily accommodates various flow rates. Various mobile phase compositions were employed to separate PSE, PAR and LOR. Isocratic elution conditions were found to be unsuccessful in separating all components in a short time so the system was switched to step gradient elution mode using methanol and aqueous formic acid. The best separation was obtained using $40 \%$ (v/v) methanol and $0.1 \%$ formic acid. Initially, methanol content was set to $40 \%(\mathrm{v} / \mathrm{v})$ and remained isocratic for 5 min then was switched to $80 \%(\mathrm{v} / \mathrm{v})$ methanol and remained isocratic up to 10 min. Subsequently, mobile phase was brought back to $40 \%$ methanol for $2 \mathrm{~min}$ so as to regenerate the column conditions. The flow rate was $1.0 \mathrm{~mL} \mathrm{~min}^{-1}$ and total analysis time was $12 \mathrm{~min}$. Once the separation of all the components had been achieved successfully, the MS parameters (spray voltage, capillary temperature and gas flows) were optimized. ESI was carried out in positive mode. Ionization of analytes is sensitive to spray voltage in ESI hence the effect was studied in the range 3.0 to $5.0 \mathrm{kV}$. It was observed that decreasing the values showed a decrease in ionization efficiency of analytes where the best ion intensity for all the components was achieved using a spray voltage of $4.5 \mathrm{kV}$. Therefore, $4.5 \mathrm{kV}$ was selected as the optimum ionization potential. The other MS parameters for ESI were optimized as sheath gas and aux/sweep gas flows at 75 and 25 arbitrary units, respectively, while capillary temperature was maintained at $225{ }^{\circ} \mathrm{C}$. Mass spectral transitions were recorded in SRM mode at $m / z, 166.2 \rightarrow m / z 148.0$ for PSE with collision energy (CE) of $28, \mathrm{~m} / \mathrm{z}, 152.0 \rightarrow \mathrm{m} / \mathrm{z}, 110.0$ for PAR with CE of $40, \mathrm{~m} / \mathrm{z} 383.0 \rightarrow$ $\mathrm{m} / \mathrm{z}, 337.0$ for LOR with CE of 38 and $\mathrm{m} / \mathrm{z}, 275.2 \rightarrow \mathrm{m} / \mathrm{z}, 230.2$ for IS with CE of 28 (Figure 1).

All other optimizations were carried out at positive ionization using corresponding $\mathrm{m} / \mathrm{z}$ for each analyte's product ion. Figure 2 shows all the components separated under optimized conditions and processed using Xcalibur software.

\section{Extraction recovery and matrix effect}

Ion suppression or enhancement is primarily caused by endogenous materials present in matrix samples while using electrospray ionization, and its extent chiefly depends on the nature of the components under investigation and sample treatment procedure employed. $^{25}$

The results obtained for PSE, PAR and LOR showed no apparent signal suppression when the protein precipitation sample clean-up procedure was adopted. Results indicate (Table 1) that the maximum recovery was achieved for LOR $(101.56 \pm 0.1 \%)$ followed by PSE $(97.78 \pm 0.3 \%)$ whereas extraction recovery for PAR was determined as $(88.13 \pm 0.3 \%)$. The extraction efficiency was found to be satisfactory, proving both consistent and reproducible. This can be attributed to the protein precipitation procedure used in this method which proved to be efficient and sufficiently simple to extract all components along with IS simultaneously from human plasma. 
(a)

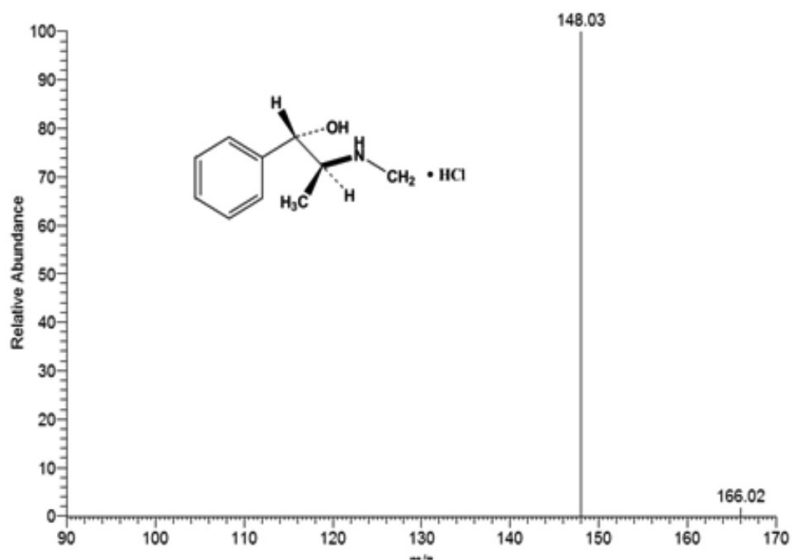

(c)

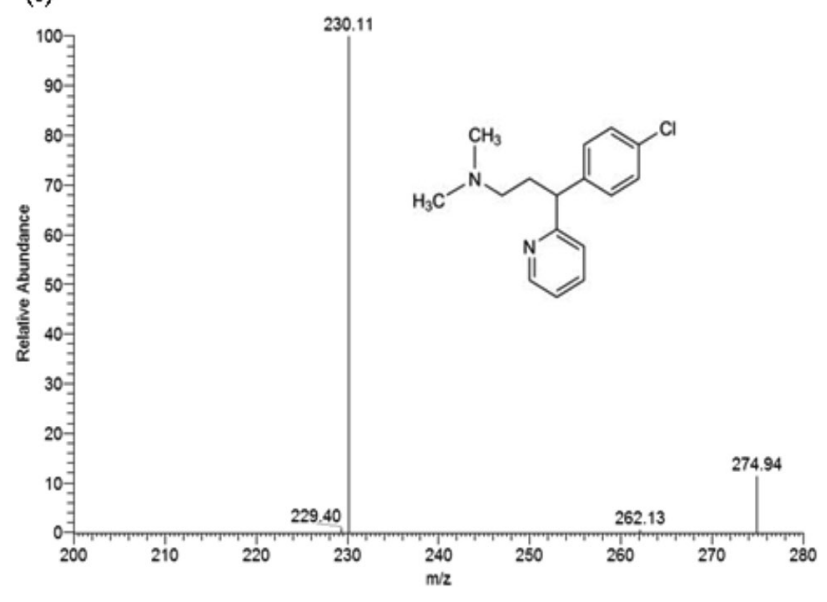

(b)

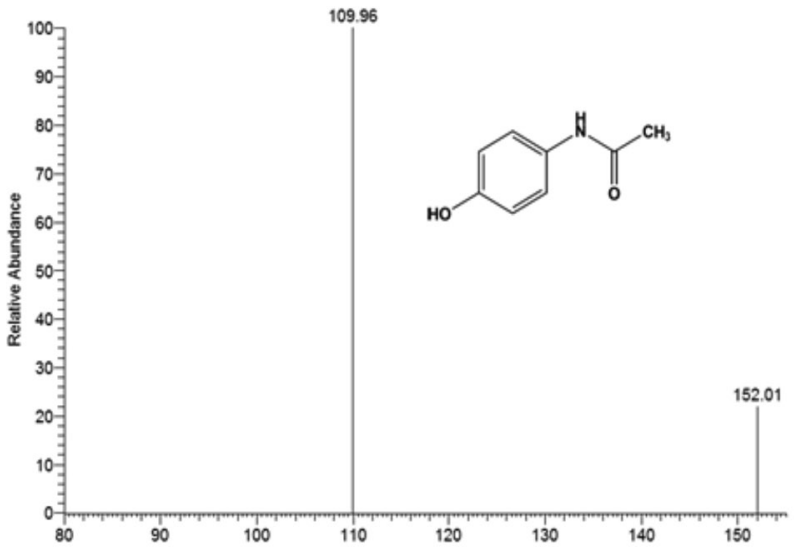

(d)

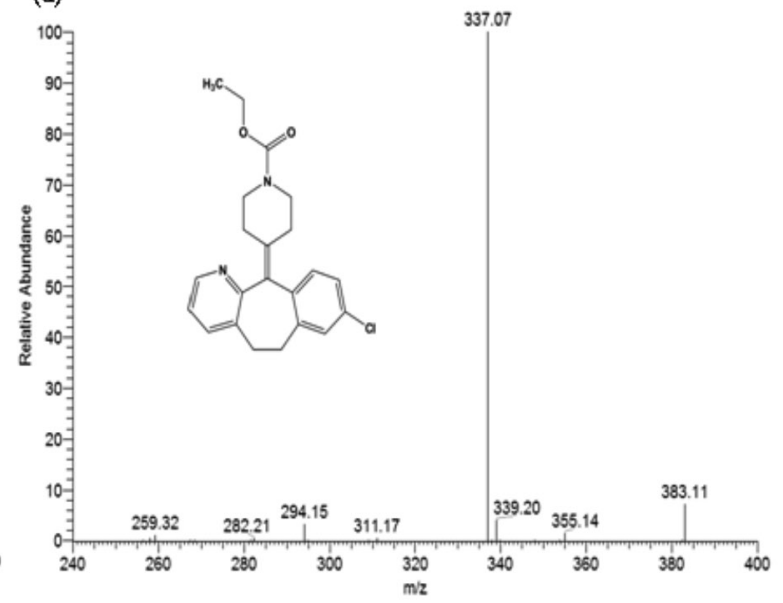

Figure 1. Product ion spectra showing the pseudo-molecular ion $[M+H]^{+}$of: (a) pseudoephedrine; (b) paracetamol; (c) chlorpheniramine (internal standard) and $(d)$ loratadine

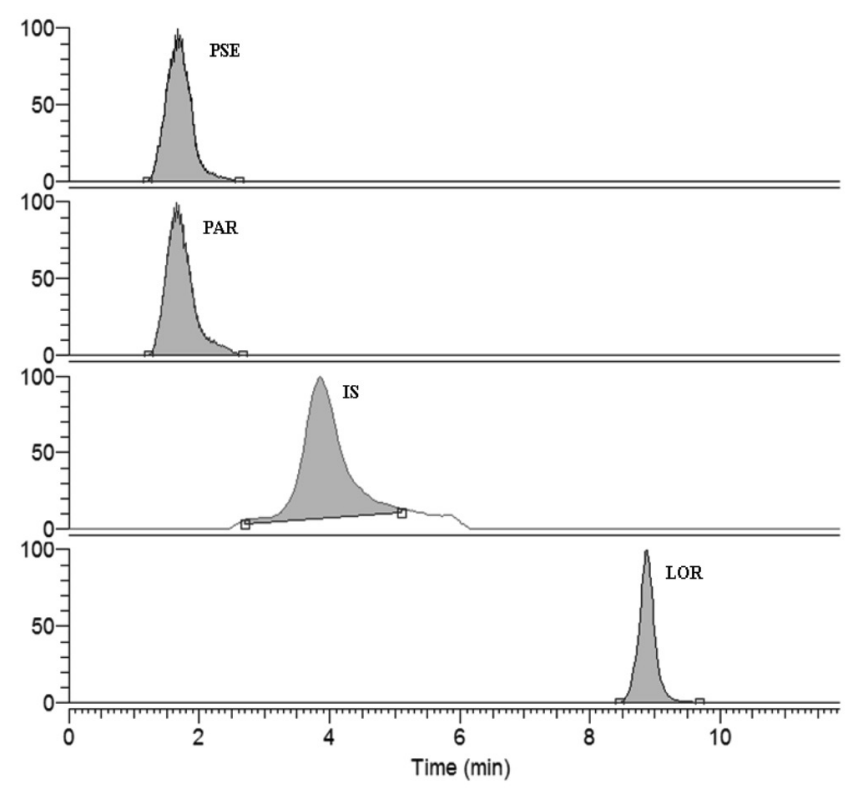

Figure 2. LC-MS/MS standard chromatogram (PSE, IS and PAR and LOR $0.1 \mu g m L^{-1}$ )

\section{System suitability, linearity and calibration}

The system suitability was calculated by reproducibility tests of retention time, number of theoretical plates, capacity factor, resolution and selectivity factor of all compounds. Linearity was monitored using linear regression. The linearity range for PSE, PAR and LOR was found to lie between 0.03 and $10 \mu \mathrm{g} \mathrm{mL}^{-1}$ with regression coefficients of $0.992,0.995$ and 0.997 , respectively. The internal standard calibration of PSE, PAR and LOR was constructed in the range 0.078 to $5.0 \mu \mathrm{g} \mathrm{mL}^{-1}$ (Table 2).

\section{Limit of detection and limit of quantitation}

Standard calibration was used to construct the calibration curve to calculate LOD and LOQ, which can be expressed as 3.3 and 10 times the ratio of the standard error of intercept and slope of the curve, respectively. Limit of detection and quantitation for PSE, PAR and LOR were determined as 3.14, 1.86 and $1.44 \mathrm{ng} \mathrm{mL}^{-1}$ and 10.47, 6.21 and $4.81 \mathrm{ng} \mathrm{mL}^{-1}$, respectively (Table 2).

\section{Within-laboratory determinations}

Within-laboratory determinations were analyzed by intraday and interday precision analysis. Intraday and interday precision analyses were performed at the three different concentrations of $0.625,1.25$ and $2.5 \mu \mathrm{g} \mathrm{mL}^{-1}$ for PSE, PAR and LOR standards for 5 times a day and 5 consecutive days. The precision of drugs were evaluated for accuracy (\%) with CV (\%) response in both intraday and interday reproducibility determinations. The accuracy (\%) of PSE, PAR and LOR for intraday precision data analysis was determined to be in the range 89.6 to $101.64 \%$ with $\mathrm{CV}(\%)$ in the range 0.8 to 3.54 . The accuracy $(\%)$ of PSE, PAR and LOR for interday precision data analysis 
Table 1. Precision, accuracy and extraction recovery for LOR, PSE, PAR and CPM in plasma samples

\begin{tabular}{|c|c|c|c|c|c|c|}
\hline \multirow[b]{2}{*}{ Component } & \multirow{2}{*}{$\begin{array}{c}\text { Nominal } \\
\text { concentration } \\
(\mu \mathrm{g} / \mathrm{mL})\end{array}$} & \multicolumn{2}{|c|}{ Intra-day $(n=6)$} & \multicolumn{2}{|c|}{ Inter-day $(n=6)$} & \multirow{2}{*}{$\begin{array}{c}\text { Extract recovery } \\
\qquad(\%) \\
(\mathrm{n}=6)\end{array}$} \\
\hline & & $\begin{array}{l}\text { Measured concen- } \\
\text { tration }(\mu \mathrm{g} / \mathrm{mL})\end{array}$ & $\begin{array}{l}\mathrm{CV} \\
(\%)\end{array}$ & $\begin{array}{l}\text { Measured concen- } \\
\text { tration }(\mu \mathrm{g} / \mathrm{mL})\end{array}$ & $\begin{array}{l}\mathrm{CV} \\
(\%)\end{array}$ & \\
\hline \multirow[t]{3}{*}{ PSE } & 0.625 & $0.629 \pm 0.02$ & 3.18 & $0.621 \pm 0.02$ & 3.22 & $98.70 \pm 0.1$ \\
\hline & 1.25 & $1.28 \pm 0.02$ & 1.56 & $1.23 \pm 0.04$ & 3.25 & $97.78 \pm 0.3$ \\
\hline & 2.5 & $2.52 \pm 0.04$ & 1.59 & $2.46 \pm 0.06$ & 2.44 & $99.32 \pm 0.2$ \\
\hline \multirow[t]{3}{*}{ PAR } & 0.625 & $0.565 \pm 0.02$ & 3.54 & $0.571 \pm 0.03$ & 5.25 & $88.57 \pm 0.4$ \\
\hline & 1.25 & $1.12 \pm 0.03$ & 2.68 & $1.11 \pm 0.04$ & 3.60 & $88.13 \pm 0.3$ \\
\hline & 2.5 & $2.31 \pm 0.04$ & 1.73 & $2.28 \pm 0.06$ & 2.63 & $89.32 \pm 0.4$ \\
\hline \multirow[t]{3}{*}{ LOR } & 0.625 & $0.626 \pm 0.01$ & 1.60 & $0.624 \pm 0.02$ & 3.21 & $101.56 \pm 0.1$ \\
\hline & 1.25 & $1.25 \pm 0.01$ & 0.80 & $1.24 \pm 0.03$ & 2.42 & $100.23 \pm 0.2$ \\
\hline & 2.5 & $2.51 \pm 0.03$ & 1.20 & $2.49 \pm 0.03$ & 1.21 & $101.16 \pm 0.1$ \\
\hline \multirow[t]{3}{*}{ IS } & 0.625 & $0.622 \pm 0.02$ & 3.22 & $0.623 \pm 0.02$ & 3.21 & $100.42 \pm 0.2$ \\
\hline & 1.25 & $1.26 \pm 0.02$ & 1.59 & $1.24 \pm 0.03$ & 2.42 & $101.15 \pm 0.1$ \\
\hline & 2.5 & $2.51 \pm 0.03$ & 1.20 & $2.48 \pm 0.05$ & 2.02 & $99.39 \pm 0.2$ \\
\hline
\end{tabular}

Table 2. System suitability and validation parameters

\begin{tabular}{|c|c|c|c|}
\hline & PSE & PAR & LOR \\
\hline Repeatability of time, $\mathrm{t}_{\mathrm{R}}{ }^{\mathrm{a}}$ & $1.66 \pm 0.02$ & $1.64 \pm 0.01$ & $8.89 \pm 0.01$ \\
\hline Capacity factor & 1.91 & 1.88 & 14.6 \\
\hline Resolution & 0.5 & 0.38 & 2.97 \\
\hline Selectivity factor & -- & 0.98 & 2.49 \\
\hline $\begin{array}{l}\text { Linearity } \\
\left(\mu \mathrm{g} \mathrm{mL} L^{-1}\right)\end{array}$ & $0.039-10$ & $0.039-10$ & $0.039-10$ \\
\hline $\begin{array}{l}\text { Limit of detection } \\
\left(\mathrm{ng} \mathrm{mL} \mathrm{mL}^{-1}\right)\end{array}$ & 3.14 & 1.86 & 1.44 \\
\hline $\begin{array}{l}\text { Limit of quantification } \\
(\mathrm{ng} \mathrm{mL}-1)\end{array}$ & 10.47 & 6.21 & 4.81 \\
\hline
\end{tabular}

(a)

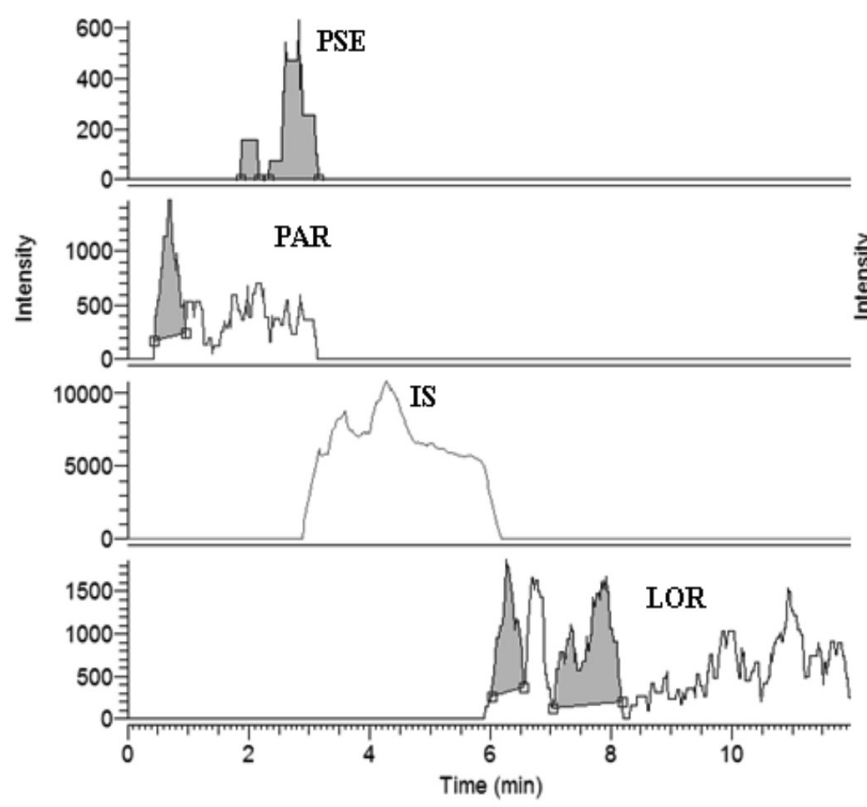

was determined to be in the range 88.8 to 99.8 with $\mathrm{CV}(\%)$ in the range 1.21 to 5.25. The precision for PSE, PAR and LOR for both interday and intraday reproducibility determinations was found to be $<6 \%$, showing the method to be suitable for routine analysis (Table 1).

\section{Clinical and pharmaceutical applications}

In the current study method, plasma samples from five healthy volunteers were analyzed by spiking with mixed standard solutions. The applications in plasma samples were carried out in duplicate. Blank and spiked plasma samples were analyzed. Extraction recovery $(\%)$ of PSE, PAR and LOR in spiked plasma samples was determined as $97.78,88.13$ and $101.56 \%$, respectively (Figure 3 ).

Pharmaceutical tablet samples were prepared as per the abovementioned procedure and analyzed using the currently developed method. The results showed good agreement of percent recovery and

(b)

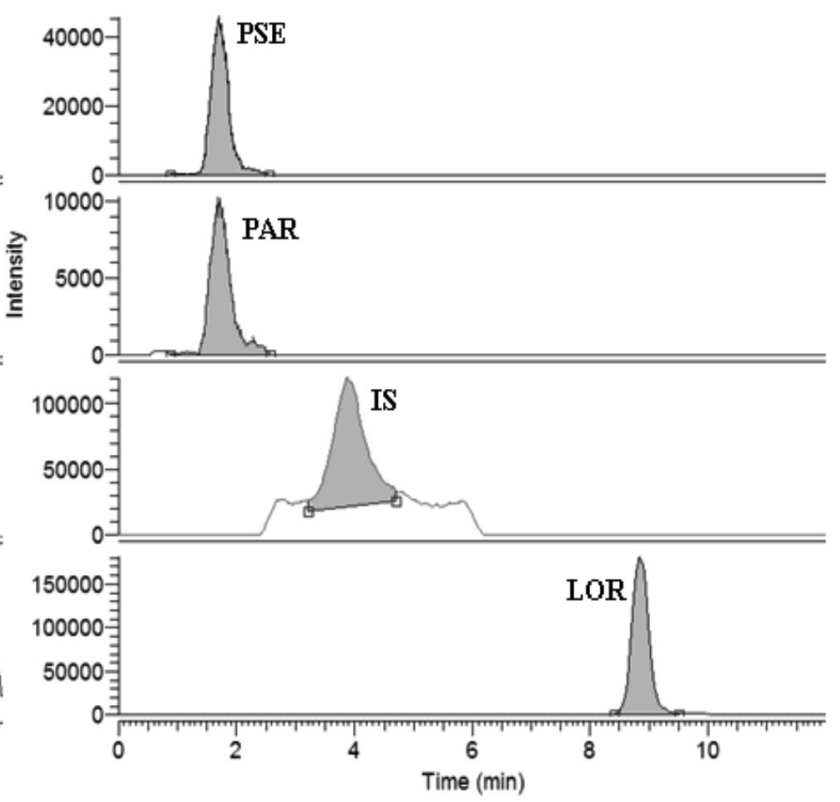

Figure 3. LC-MS/MS chromatogram of human blank plasma (a) and spiked plasma sample (containing PSE, IS and PAR $0.5 \mu \mathrm{g} m L^{-1}$ and LOR $\left.0.1 \mu \mathrm{g} m L^{-1}\right)(\mathrm{b})$ 
label claim for PSE, PAR and LOR from the manufacturer, which was determined to be $98.45,99.97$ and $99.60 \%$ with the CV (\%) of $0.02,0.01$ and 0.4 , respectively (Table 3 ).

Table 3. Assay values of PSE, PAR and LOR from pharmaceutical tablets $(\mathrm{n}=3)$

\begin{tabular}{ccccc}
\hline Component & $\begin{array}{c}\text { Amount } \\
\text { taken } \\
(\mathrm{mg})\end{array}$ & $\begin{array}{c}\text { Amount } \\
\text { recovered } \\
(\mathrm{mg})\end{array}$ & $\begin{array}{c}\mathrm{CV} \\
(\%)\end{array}$ & $\begin{array}{c}\text { Mean } \\
\text { recovery } \\
(\%)\end{array}$ \\
\hline PSE & 7.5 & $7.52 \pm 0.01$ & 0.13 & 100.27 \\
& 30 & $30.03 \pm 0.02$ & 0.07 & 100.10 \\
& 60 & $59.07 \pm 0.01$ & 0.02 & 98.45 \\
\hline PAR & 4 & $4.01 \pm 0.02$ & 0.50 & 100.25 \\
& 40 & $40.06 \pm 0.03$ & 0.07 & 100.15 \\
& 400 & $399.88 \pm 0.02$ & 0.01 & 99.97 \\
\hline LOR & 1.25 & $1.26 \pm 0.01$ & 0.79 & 100.80 \\
& 2.5 & $2.49 \pm 0.03$ & 1.20 & 99.60 \\
& 5 & $5.01 \pm 0.02$ & 0.40 & 100.20 \\
\hline
\end{tabular}

\section{CONCLUSION}

A simple, rapid and sensitive multi-component method for determination of PSE, PAR and LOR using LC-ESI-MS/MS utilizing a monolithic column has been developed. The assay achieved good sensitivity and specificity for the determination of PSE, PAR and LOR in human plasma and pharmaceutical formulations. Interference caused by the endogenous compounds was successfully eliminated. This simple and sensitive method is suitable for the pharmacokinetic study of PSE, PAR and LOR in human subjects and pharmaceutical formulations, and can also be used as a diagnostic method in clinical analysis.

\section{ACKNOWLEDGMENT}

The authors are very much thankful to "Birds Chemotec" Karachi, Pakistan for providing pharmaceutical standards and also to PCSIR laboratories Complex Karachi for providing the facilities to complete the research.

\section{REFERENCES}

1. Parfitt, K.; Martindale, W.; Martindale: The complete drug reference, $32^{\text {nd }}$ ed., Pharmaceutical Press: London, 1999.

2. Clark, R.; Borirakchanyavat, V.; Davidson, A. R.; Williams, R.; Thompson, R. P. H.; Widdop, B.; Goulding, R.; Lancet 1973, 301, 66.
3. Prescott, L. F.; Roscoe, P.; Wright, N.; Brown, S. S.; Lancet 1971, 297, 519.

4. Hwang, S. S.; Gorsline, J.; Louie, J.; Dye, D.; Guinta, D.; Hamel, L.; J. Clin. Pharmacol. 1995, 35, 259.

5. Naidong, W.; Addison, T.; Schneider, T.; Jiang, X.; Halls, T. D. J.; J. Pharm. Biomed. Anal. 2003, 32, 609.

6. Yin, O. Q. P.; Shi, X.; Chow, M. S. S.; J. Chromatogr., B: Anal. Technol. Biomed. Life Sci. 2003, 796, 165.

7. Sun, J.; Wang, G.; Wang, W.; Zhao, S.; Gu, Y.; Zhang, J.; Huang, M.; Shao, F.; Li, H.; Zhang, Q.; Xie, H.; J. Pharm. Biomed. Anal. 2005, 39, 217.

8. Ma, M.; Feng, F.; Sheng, Y.; Cui, S.; Liu, H.; J. Chromatogr., B: Anal. Technol. Biomed. Life Sci. 2007, 846, 105.

9. Li, H.; Zhang, C.; Wang, J.; Jiang, Y.; Fawcett, J. P.; Gu, J.; J. Pharm. Biomed. Anal. 2010, 51, 716.

10. Salem, I. I.; Idrees, J.; Al Tamimi, J. I.; J. Pharm. Biomed. Anal. 2004, 34, 141.

11. Chen, X.; Huang, J.; Kong, Z.; Zhong, D.; J. Chromatogr., B: Anal. Technol. Biomed. Life Sci. 2005, 817, 263.

12. Lou, H.-g.; Yuan, H.; Ruan, Z.-r.; Jiang, B.; J. Chromatogr., B: Anal. Technol. Biomed. Life Sci. 2010, 878, 682.

13. Liao, Q.; Xie, Z.; Pan, B.; Zhu, C.; Yao, M.; Xu, X.; Wan, J.; Chromatographia 2008, 67, 687.

14. Zou, H.; Gao, S.; Chen, W.; Zhong, Y.; Jiang, X.; Pei, Y.; Chromatographia 2008, 68, 251.

15. Ponnuru, V. S.; Challa, B. R.; Nadendla, R.; J. Pharm. Anal. (2012), doi:10.1016/j.jpha.2012.01.008.

16. Tan, Q.-y.; Zhu, R.-h.; Li, H.-d.; Wang, F.; Yan, M.; Dai, L.-b.; J. Chromatogr., B: Anal. Technol. Biomed. Life Sci. 2012, 893-894, 162.

17. Manassra, A.; Khamis, M.; el-Dakiky, M.; Abdel-Qader, Z.; Al-Rimawi, F.; J. Pharm. Biomed. Anal. 2010, 51, 991.

18. Rambla-Alegre, M.; Peris-Vicente, J.; Esteve-Romero, J.; Capella-Peiró, M.-E.; Bose, D.; Anal. Chim. Acta 2010, 666, 102.

19. Mirmahdieh, S.; Khayamian, T.; Saraji, M.; Microchim. Acta 2012, 176, 471.

20. Tang, J.; Zhou, X.; Ji, H.; Xu, N.; Liu, H.; Lan, G.; Wu, L.; Chromatographia 2011, 73, 761.

21. Rieux, L.; Niederländer, H.; Verpoorte, E.; Bischoff, R.; J. Sep. Sci. 2005, 28, 1628.

22. Zabka, M.; Minceva, M.; Rodrigues, A. R. E.; J. Biochem. Biophys. Methods 2007, 70, 95.

23. Bedor, D. C. G.; de Souza Filho, J. H.; Ramos, V. L. S.; Gonçalves, T. M.; de Sousa, C. E. M.; de Santana, D. P.; Quim. Nova 2011, 34, 950.

24. Faria, A. M.; Bottoli, C. B. G.; Jardim, I. C. S. F.; Collins, C. H.; Quim. Nova 2006, 29, 300.

25. van Eeckhaut, A.; Lanckmans, K.; Sarre, S.; Smolders, I.;Michotte, Y.; J. Chromatogr., B: Anal. Technol. Biomed. Life Sci. 2009, 877, 2198. 